\title{
Characteristic Rainfall for Warning of Debris Flows
}

\author{
HU Kaiheng",2*, Cui Peng,,2, Wang Chuanchang1,2, Li Yong1,2, Lu Xiaobing3 \\ 1 Key Laboratory of Mountain Hazards and Earth Surface Processes, Chinese Academy of Sciences, Chengdu, 610o41, China \\ 2 Institute of Mountain Hazards and Environment, Chinese Academy of Sciences \& Ministry of Water Conservancy, \\ Chengdu, 610041, China \\ 3 Institute of Mechanics, Chinese Academy of Sciences, Beijing, 10oo8o, China \\ *Corresponding author, E-mail: khhu@imde.ac.cn
}

(C) Science Press and Institute of Mountain Hazards and Environment, CAS and Springer-Verlag Berlin Heidelberg 2010

\begin{abstract}
A characteristic rainfall is introduced to overcome the difficulties encountered in determining a critical rainfall value for triggering debris flow. The characteristic value is defined as the rainfall at which debris-flow occurrence probability shows a rapid increase, and can be used as a warning rainfall threshold for debris flows. Investigation of recorded debris flows and 24-hour rainfall data at Jiangjia basin, Yunnan Province, in southwestern China, demonstrates the existence of such a characteristic rainfall. It was found that the characteristic rainfall corresponds to the daily rainfall of $90 \%$ cumulative probability by analyzing the basin's daily rainfall histogram. The result provides a simple and useful method for estimating a debris-flow warning rainfall threshold from the daily rainfall distribution. It was applied to estimate the debris-flow warning rainfall threshold for the Subaohe basin, a watershed in the 2008 Wenchuan earthquake zone with many physical characteristics similar to those of the Jiangjia basin.
\end{abstract}

Keywords: Debris flow; Wenchuan earthquake; warning rainfall threshold; statistics of daily rainfall distribution

\section{Introduction}

Many rainfall-induced debris flows are mobilized from shallow landslides (Iverson et al., 1997; Gabet and Mudd, 2006). Both processes are due to an increase in pore water pressure caused by

Received: 20 January 2010

Accepted: 1 May 2010 rainfall infiltration (Iverson, 2000). Physical and statistical models have been developed to find the correlation between their occurrence and rainfall (Caine, 1980; Montgomery and Dietrich, 1994), and different triggering criteria, i.e. thresholds, for shallow landslides and debris flows have been proposed (Caine, 1980; Cannon and Ellen, 1985; Wieczorek, 1987; Casadel et al., 2003; Chen et al., 2005; Godt et al., 2006).

However, the threshold depends strongly on local physiographic, hydrological and meteorological conditions, and is not unique. For instance, the $24 \mathrm{~h}$ (24 hours) cumulative rainfall for triggering debris flows is larger than $100 \mathrm{~mm}$ in Taiwan whereas a rainfall with a $24 \mathrm{~h}$ amount of 20 50 $\mathrm{mm}$ can easily cause debris flows in the Xiaojiang River basin in Yunnan. The intensityduration threshold is also different in Seattle, Washington (Godt et al., 2006; Chen et al., 2005). Cannon and Ellen (1985) proposed that the rainfall intensity values should be normalized by the mean annual precipitation (MAP) in order to account for different climatic domains. Taking into account the difference in MAP and the annual number of rainy days (RDN), Wilson $(1997,2000)$ presented a procedure for transferring rainfall thresholds among different regions.

However, even for a certain basin, the rainfall threshold is not constant. For instance, a rainfall far below the threshold can trigger debris flows when material supplies or slope failures are extensive, as in the case of valleys suffering 
earthquakes (Cui et al., 2009; Lin et al.,2004) Therefore, it is hard to define the rainfall threshold both literally and physically.

Nevertheless, in most cases there exists a characteristic value of rainfall below which debris flows are unlikely to occur but above which they are likely. Compared with the critical rainfall, the characteristic rainfall is more accurate, and more suitable to serve as a warning threshold. But estimating the characteristic rainfall requires longterm data for debris-flow events and related rainfall, which is unrealistic for most debris-flow basins. For example, in the Longmenshan area of northwestern Sichuan Province, China, where a 8.0 Ms earthquake occurred 12 May, 2008, many debris flow events occurred after the earthquake and resulted in vast life and property losses. The local government is in urgent need of a reliable approach for calculating the warning rainfall threshold, but only one year of monitoring rainfall data in debris-flow-affected areas is not enough for deducing the characteristic rainfall.

This paper presents a simple approach to estimating the characteristic rainfall. The required data are only the local daily rainfall distributions. In general, debris flows are not as common as shallow landslides, and for most debris-flow basins only a single event may happen over many years. Because debris flows do not happen frequently, most rainfall processes and events do not trigger them. This implies that debris-flow warning rainfall is a low-frequency rainfall event. Such a connection between the characteristic rainfall and the statistics of daily rainfall was found by investigating the records of debris-flow and rainfall events from 2002 to 2008 at Jiangiia basin of the Xiaojiang River. Then, those results were applied to estimate the characteristic rainfall in the Subaohe basin in the 2008 Wenchuan earthquake area.

\section{Study Areas}

\subsection{Physical settings}

The study areas are Jiangjia and Subaohe basins (Figure 1). They share similarities in some physiographic, geological, and climatic characteristics (Table 1). Both are small upstream tributaries of the Yangtze River: Jiangjia to the Xiaojiang River and Subaohe to the Anchanghe River. The Jiangjia and Subaohe basins lie, respectively, in the Hengduanshan and Longmenshan Mountain areas in southwestern China, each with several large faults on which earthquakes happen frequently. Six earthquakes with magnitude $>5.5$ Ms occurred in the Xiaojiang region in the years 1893, 1911, 1930, 1947, 1966, and 1985. The epicenter of the 6.5 Ms earthquake in 1966 was located at the mouth of the Jiangjia basin. Similarly, the Subaohe basin was located in the meizoseismal central area of the 2008 Wenchuan earthquake, and the Yingxiu-Beichuan Fault of Longmenshan passes by the basin's distal area, extending from Yingxiu (the epicenter of the earthquake) to Beichuan with a NE 35 45 degree orientation. In addition to the effects of intensive earthquakes, lithological units in the two areas primarily consist of metamorphic or clastic rocks such as slate, phyllite, and sandstone. These rocks are soft and readily weathered into disaggregated debris. The subtropical humid monsoon, under conditions of Pacific high pressure in summer, dominates both Xiaojiang and Beichuan's climate. More than $80 \%$ of the annual rainfall occurs in the summer rainy season at Jiangjia, compared to approximately $75 \%$ at Subaohe. Maximum annual rainfall is as high as $2340 \mathrm{~mm}$ in Beichuan County. Both of the study areas are characterized by altitudinal zonation of rainfall. Rainfall at high altitude can be twice that at low altitude. More

Table 1 Comparison of the two areas' physical settings

\begin{tabular}{|c|c|c|c|c|c|}
\hline Basin & $\begin{array}{c}\text { Area } \\
\left(\mathrm{km}^{2}\right)\end{array}$ & $\begin{array}{c}\text { Relative } \\
\text { elevation }(\mathrm{m})\end{array}$ & River system & $\begin{array}{c}\text { Annual rainfall } \\
(\mathrm{mm})\end{array}$ & Rainy season \\
\hline Jiangjia & 48.6 & 2227.0 & Yangtze & $700 \sim 1,200$ & Jun. to Sep. \\
\hline Subaohe & $106.3^{*}$ & 1710.0 & Yangtze & $\mathbf{1 , 1 0 0 ~ 1 , 5 0 0}$ & Jun. to Sep. \\
\hline
\end{tabular}

${ }^{*}$ Note: The area of Subaohe includes the adjacent basin of Weijiagou. 


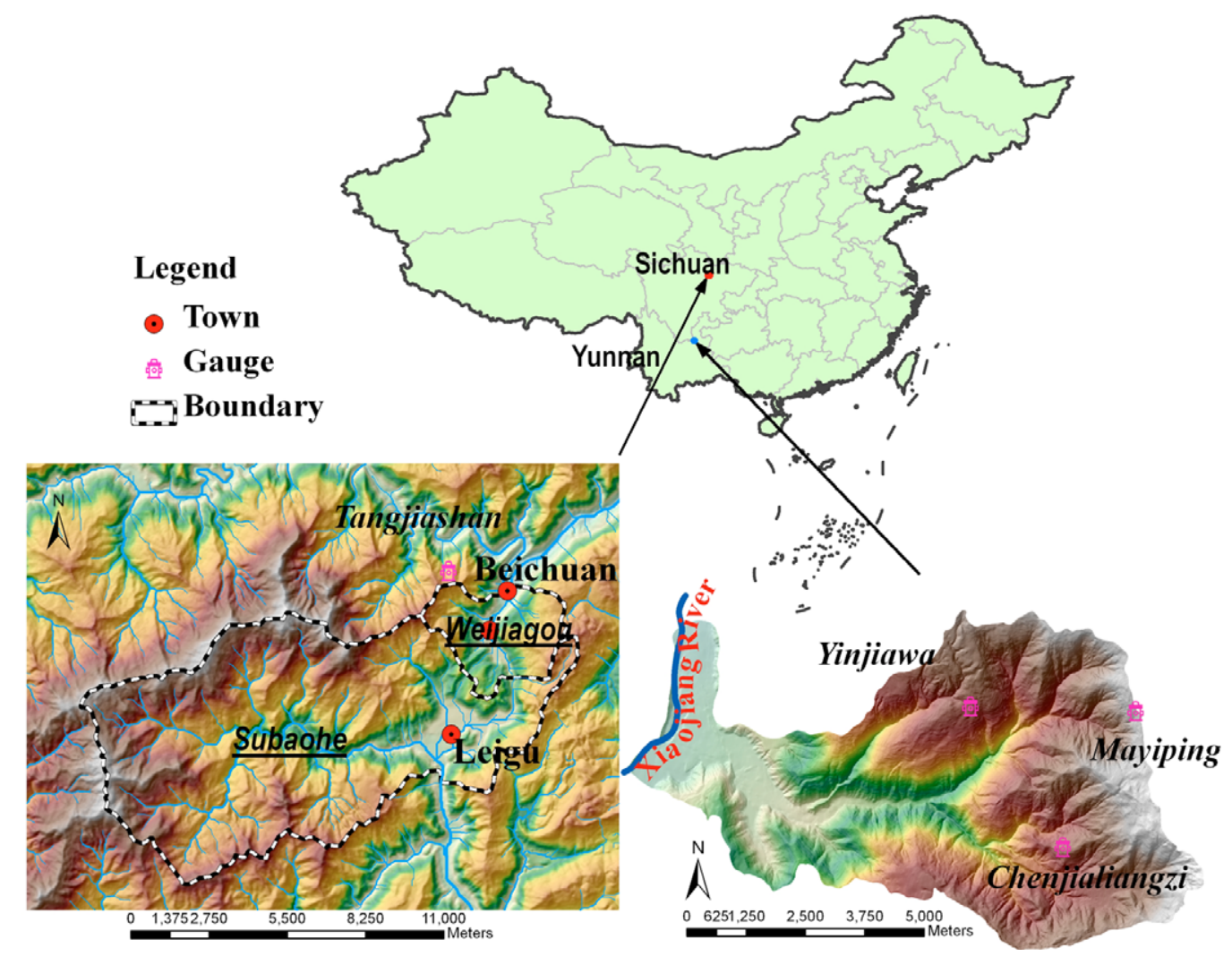

Figure 1 Maps of Jiangjia and Subaohe basins, showing rainfall gauging sites (Subaohe basin on the left, Jiangjia basin on the right)

information about the study areas and their debris flows can be found in Kang and Zhang (1980), Li et al. (1983), and Cui et al. (2005, 2009).

Under the influences of differing physical conditions, the two basins belong to transportlimited or supply-unlimited systems of debris flow formation (Bovis and Jakob, 1999). In contrast with weathered-limited or supply-limited systems, debris-flow activity of a supply-unlimited system is controlled primarily by rainfall conditions, and not dependent on the volume of debris material. For supply-unlimited basins, the relationship between rainfall and debris-flow occurrence can be observed more clearly because there are no limits on debris supply. Considering this similarity in condition, we can assume that the approach to determining the warning rainfall threshold on the basis of Jiangjia's data can also be applied to Subaohe basin.

\subsection{Daily rainfall distributions at Jiangiia and Subaohe basins}

Since 2002, Dongchuan Debris Flow
Observation and Research Station (DDFORS), a facility of the Institute of Mountain Hazards and Environment, Chinese Academy of Sciences, has set up nine wireless rainfall gauges distributed in upstream and downstream portions of Jiangjia basin (Figure 1). The gauges can record rainfall once per minute and store the data. In addition, the station has installed monitoring instruments including ultrasonic sensors, geophone detectors, and video cameras in the middle reaches of Jiangjia. The occurrence time of the debris-flow events was determined from monitoring data and the station records.

However, we do not have similar instrumentation in the Subaohe basin. Just after the earthquake, the Chinese government constructed an automatic meteorological station in the vicinity of the Tangjiashan landslide next to the basin in order to monitor the Tangjiashan dammed lake (Figure 1). For our purposes, only one year of rainfall data is not adequate for calculating a significant cumulative rainfall histogram. Fortunately, daily precipitation distribution can be extracted from Tropical Rainfall Measuring 


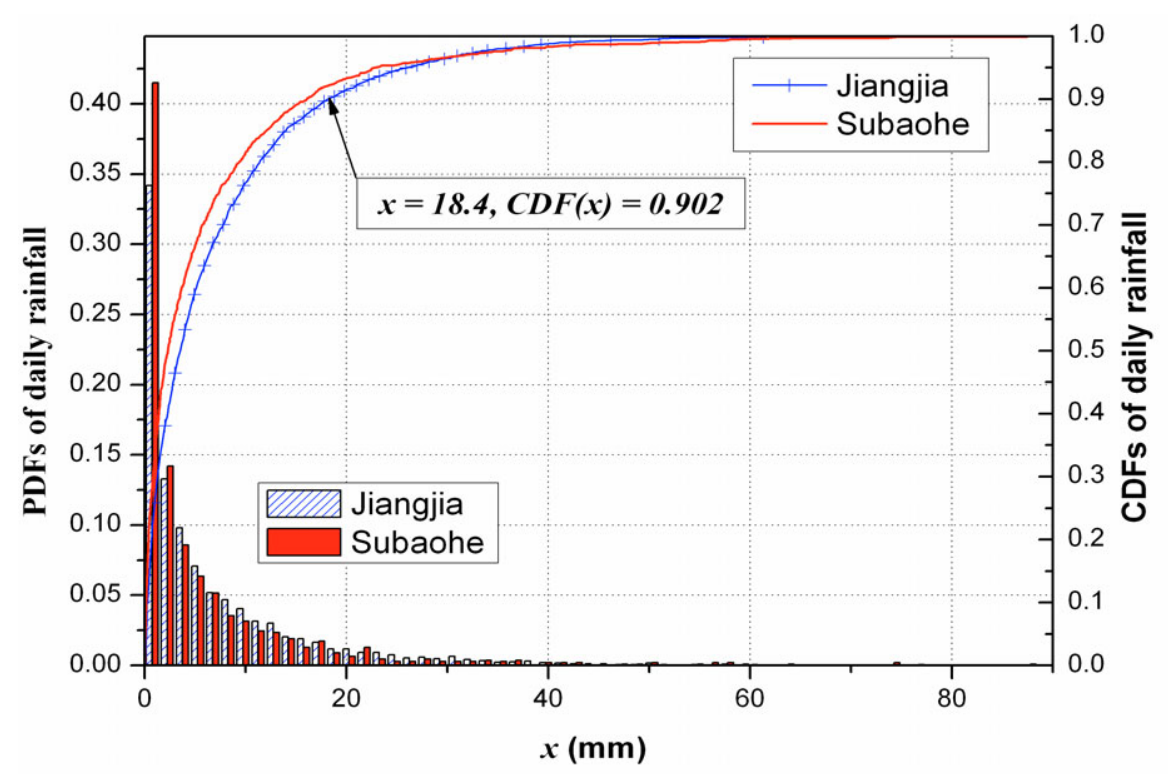

Figure 2 Histograms of daily rainfall at the Jiangjia and Subaohe basins (Jiangjia from 2002 to 2008; Subaohe from 1998 to 2008. The interval of each bar of the histogram is $1.5 \mathrm{~mm}$.)

Mission (TRMM) published data. The extracted data is the mean rainfall over a $0.25^{\circ} \times 0.25^{\circ}$ area (E $104^{\circ} 15^{\prime} \sim 104^{\circ} 30^{\prime}, \mathrm{N} 31^{\circ} 45^{\prime} \sim 32^{\circ} \mathrm{Oo}$ ') which lies in Beichuan County. Subaohe basin is approximately one-ninth of that area.

Probability density and cumulative distribution functions (PDFs and CDFs) of daily rainfall in the two basins (Figure 2) are defined as follows:

$$
\begin{aligned}
& \operatorname{PDF}(x)=\frac{N(R=x)}{N(0<R<+\infty)}, \\
& C D F(x)=\frac{N(0<R<x)}{N(0<R<+\infty)}
\end{aligned}
$$

Here, $R$ is rainfall value, and $N(\ldots)$ is the number of rainy days with rainfall $R$ satisfying the condition in the bracket. It is noted that more than 80 percent of daily rainfall at Subaohe is below 10 $\mathrm{mm}$, and the percentage of light rainy days at Subaohe is greater than at Jiangiia. Our purpose is to find a linkage of the daily rainfall distribution to the characteristic rainfall correlating with debris flows at Jiangjia basin and then apply it to Subaohe.

\section{24-hour Cumulative Triggering Rainfall at Jiangjia Basin}

In order to find the linkage, we analyzed rainfall data measured by the Chenjialiangzi, Mayiping and Yinjiawa gauges in three main upstream tributaries of Jiangiia from which debrisflow materials are transported. 24-hour cumulative triggering rainfall, i.e. the sum of rainfall in the twenty-four hours before a debris-flow event, was utilized. Table 2 shows that debris flows can be triggered even if a rainstorm happens in only one tributary. Therefore, the maximum value of the three gauges is regarded as the $24 \mathrm{~h}$ cumulative triggering rainfall.

It is noted that rainfall as low as $10.6 \mathrm{~mm}$ (for example, 21-Jul-2004) can trigger debris flow. However, we cannot say that the minimum value $(10.6 \mathrm{~mm})$ is the threshold at Jiangjia because we cannot conclude that a rainfall above $10.6 \mathrm{~mm}$ must lead to debris flow and that a rainfall below that figure will never trigger a debris flow. Rather, we can only deduce that the probability of debrisflow occurrence is very small when the rainfall is less than $10.6 \mathrm{~mm}$. Chen (1985) proposed that rainfall during the twenty days before a debris-flow event would play a significant role on soil moisture content, and thus that effective antecedent rainfall of twenty days might dominate as a factor triggering a debris flow when compared with concurrent rainfall. From this point of view, the effective triggering rainfall was far greater than $10.6 \mathrm{~mm}$ for the event of July 21, 2004 for there 
Table 2 24-hour cumulative rainfall before triggering of a debris flow from 2002 to 2008 in Jiangjia basin

\begin{tabular}{|c|c|c|c|c|}
\hline \multirow{2}{*}{ Time of Triggering $\left(T_{o}\right)$} & \multicolumn{3}{|c|}{24 hour Cumulative Rainfall $R_{24}$ before $T_{o}(\mathrm{~mm})$} & \multirow{2}{*}{$\begin{array}{l}\text { Maximum Rainfall at the } \\
\text { three gauges }(\mathrm{mm})\end{array}$} \\
\hline & Chenjialiangzi & Mayiping & Yinjiawa & \\
\hline 18-Jul-2002 09:51 & 0.0 & $25 \cdot 5$ & 0.0 & $25 \cdot 5$ \\
\hline 15-Aug-2002 00:50 & 24.8 & 11.7 & 9.9 & 24.8 \\
\hline 16-Aug-2002 04:49 & 29.8 & 2.9 & $37 \cdot 5$ & $37 \cdot 5$ \\
\hline 16-Aug-2002 15:51 & $35 \cdot 3$ & 19.5 & 39.6 & 39.6 \\
\hline 20-Aug-2002 17:28 & 0.0 & $17 \cdot 5$ & 13.8 & $17 \cdot 5$ \\
\hline 1-Sep-2002 16:04 & 36.3 & 0.0 & 3.4 & 36.3 \\
\hline 12-Sep-2002 17:23 & 2.7 & 0.0 & 18.8 & 18.8 \\
\hline 5-Jun-2003 22:21 & $23 \cdot 3$ & 39.4 & 3.2 & 39.4 \\
\hline 11-Jun-2003 00:07 & 14.9 & 15.2 & 0.0 & 15.2 \\
\hline 22-Jun-2003 21:38 & 3.8 & 34.2 & 0.0 & 34.2 \\
\hline 18-Jul-2003 00:24 & 0.0 & 21.9 & $23 \cdot 3$ & $23 \cdot 3$ \\
\hline 26-Jul-2003 13:23 & 22.7 & 26.7 & 9.9 & 26.7 \\
\hline 10-Aug-2003 03:42 & 25.6 & 0.0 & 18.1 & 25.6 \\
\hline 10-Aug-2003 23:27 & 23.4 & 10.3 & 39.4 & 39.4 \\
\hline 26-Jun-2004 18:32 & $17 \cdot 4$ & 0.0 & 0.0 & $17 \cdot 4$ \\
\hline 9-Jul-2004 11:20 & 0.0 & 0.0 & 15.8 & 15.8 \\
\hline 19-Jul-2004 03:02 & 26.9 & 0.0 & 27.8 & 27.8 \\
\hline 21-Jul-2004 17:57 & 10.6 & o.o & 5.2 & 10.6 \\
\hline 31-Jul-2004 17:38 & 0.0 & 6.8 & 11.2 & 11.2 \\
\hline 25-Aug-2004 12:40 & 16.1 & 5.9 & 22.0 & 22.0 \\
\hline 30-Jul-2005 04:19 & 18.4 & 0.0 & 23.0 & 23.0 \\
\hline 18-Aug-2005 02:30 & 40.9 & 0.0 & $37 \cdot 3$ & 40.9 \\
\hline 5-Jul-2006 02:33 & 0.0 & 25.8 & 28.8 & 28.8 \\
\hline 6-Jul-2006 03:35 & 0.0 & $23 \cdot 4$ & 9.0 & 23.4 \\
\hline 15-Aug-2006 21:59 & 0.0 & 31.9 & 17.2 & 31.9 \\
\hline 20-Aug-2006 23:45 & 0.0 & $4 \cdot 4$ & 18.5 & 18.5 \\
\hline 10-Jul-2007 04:20 & 10.1 & 11.8 & 22.1 & 22.1 \\
\hline 24-Jul-2007 06:30 & 17.7 & 18.1 & 18.4 & 18.4 \\
\hline 25-Jul-2007 02:36 & 34.6 & 29.2 & 42.6 & 42.6 \\
\hline 25-Jul-2007 14:24 & 43.1 & $54 \cdot 3$ & 37.9 & $54 \cdot 3$ \\
\hline 30-Jul-2007 05:40 & 19.8 & $17 \cdot 9$ & 13.4 & 19.8 \\
\hline 11-Aug-2007 14:27 & 22.3 & 15.8 & 33.7 & $33 \cdot 7$ \\
\hline 14-Sep-2007 01:30 & 18.4 & 20.1 & 25.8 & 25.8 \\
\hline
\end{tabular}




\begin{tabular}{|c|c|c|c|c|}
\hline 17-Sep-2007 15:12 & 20.9 & 23.9 & 27.7 & 27.7 \\
\hline 1-Jul-2008 15:55 & 0.0 & 33.0 & 26.9 & 33.0 \\
\hline 5-Jul-2008 06:26 & 0.0 & 19.6 & 19.9 & 20.9 \\
\hline 11-Jul-2008 06:48 & 0.0 & $7 \cdot 7$ & 20.9 & 32.8 \\
\hline 11-Jul-2008 17:46 & 0.0 & 14.1 & 32.8 & 22.1 \\
\hline 22-Jul-2008 05:00 & 21.4 & 22.1 & 15.3 \\
\hline 31-Jul-2008 00:15 & 4.3 & 0.1 & 15.0 & 22.6 \\
\hline 3-Aug-2008 04:50 & 7.5 & 22.6 & 9.7 & 25.2 \\
\hline 3-Aug-2008 20:10 & 11.2 & 25.2 & 17.0 & 15.3 \\
\hline 4-Aug-2008 10:09 & 10.4 & 8.8 & $15 \cdot 3$ & 17.3 \\
\hline 5-Aug-2008 13:56 & 0.1 & 11.7 & 17.3 & 30.6 \\
\hline 8-Aug-2008 03:00 & 20.3 & 30.6 & 12.0 & 18.4 \\
\hline 11-Aug-2008 02:16 & 16.0 & 0.7 & 18.4 & \\
\hline
\end{tabular}

were at least two intense rain storms, on July 9 and 19. But, as mentioned in the introduction, our purpose is to find the characteristic rainfall based on limited rainfall data but not to seek an absolute but uncertain value for triggering rainfall.

\section{Determination of the Characteristic Rainfall}

In order to determine the characteristic rainfall, a new variable, named the catastrophic ratio, is defined as:

$$
P(x)=\frac{N_{f}\left(R_{24}>x\right)}{N(R>x)}
$$

where $P(x)$ denotes the catastrophic ratio, $N_{f}$ is the number of debris-flow events with $R_{24}$ greater than $x$, and $N$ is the number of rainy days of rainfall $R$ greater than $x$. The variable describes the probability of debris flows when rainfall is greater than $x$.

The $P(x)$ vs. $x$ curve has three distinct sections (Figure 3): monotonously increasing, fluctuating, and decreasing sections. $P$ increases linearly with $x$ in the increasing section, which indicates that $N$ decreases more rapidly than $N_{f}$ as rainfall increases when $x<18.4 \mathrm{~mm}$. As $x$ reaches $18.4 \mathrm{~mm}$, the curve fluctuates and $N$ and $N_{f}$ keep decreasing at similar rates. It is surprising that the maximum catastrophic ratio is 0.4 , which means that the probability of debris-flow occurrence at Jiangjia is less than $40 \%$ no matter how large a rainstorm is. Beyond the fluctuating section of the plot $(>38.4$ $\mathrm{mm}$ ), the curve varies in a complex manner. $P$ decreases generally with $x$ in the last section. The variation in the catastrophic ratio indicates that the probability of debris-flow occurrence does not correlate absolutely with increasing rainfall. From o to $18.4 \mathrm{~mm}$, the tendency for cause and effect increases. Between 18.4 to $38.4 \mathrm{~mm}$, it fluctuates. When $x>38.4 \mathrm{~mm}$, the probability decreases. The most dangerous rainfall values range between 18.4 to $38.4 \mathrm{~mm}$. Then the first inflection point $(x=18.4$ $\mathrm{mm}$ ) can be defined as the characteristic value. The

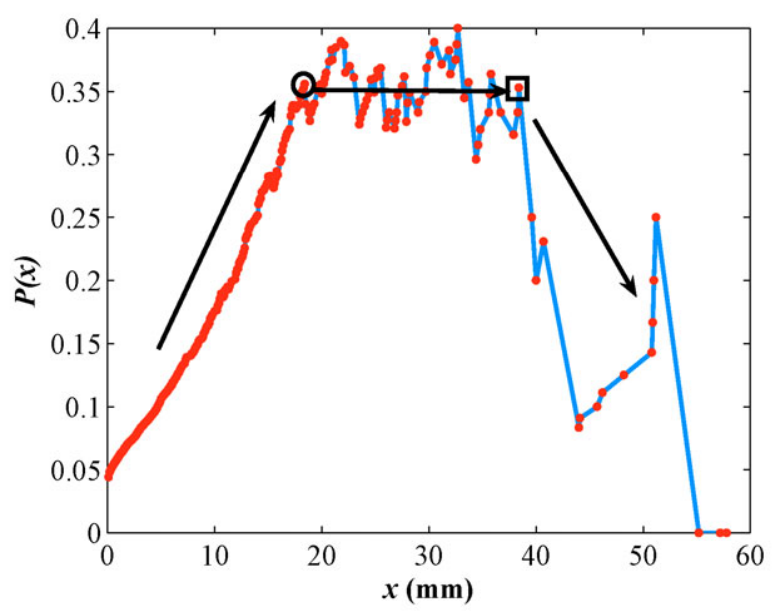

Figure 3 Catastrophic ratio $P(x)$ versus rainfall $x$ at Jiangjia basin from 2002 to 2008 (circle, $x=18.4 \mathrm{~mm}$; square, $x=38.4 \mathrm{~mm}$ ) 


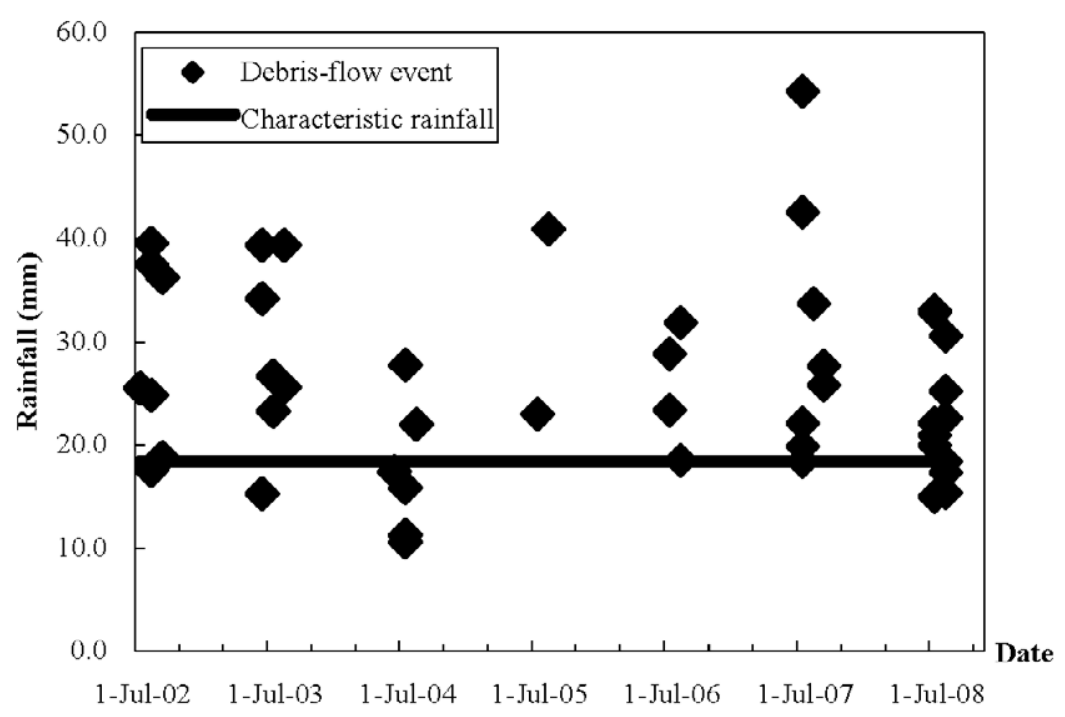

Figure 4 Debris-flow events and characteristic rainfall at Jiangjia

$24 \mathrm{~h}$ cumulative rainfalls in Table 2 and the characteristic rainfall are plotted in Figure 4.

Furthermore, it is noted that the inflection point corresponds with the rainfall value at which the cumulative probability is equal to $90 \%$ of the daily rainfall distribution of Jiangjia (Figure 2). This implies that daily rainfall with a 90\% probability $\left(R_{90}\right)$ can be used as the characteristic rainfall and that the rule can be applied to other similar basins such as Subaohe. The TRMM data at Subaohe reveals that the cumulative probability of daily rainfall reaches $90 \%$ when $x=16.2 \mathrm{~mm}$. Based on the above analyses of Jiangjia data, that value $(16.2 \mathrm{~mm})$ seems to be the characteristic rainfall for Subaohe. However, considering the TRMM spatial resolution and the local altitudinal zonality of rainfall, the value needs to be rectified with local accurate rainfall data. Daily rainfall measured at the Tangjiashan gauge on September 23, 2008 was used as the rectification value. The measured value at the gauge is $173.8 \mathrm{~mm}$ while the TRMM rainfall on that day is $74.4 \mathrm{~mm}$. Therefore, the rectified characteristic rainfall at Subaohe should be equal to $37.84 \mathrm{~mm}\left[=(173.8 / 74.4)^{*} 16.2\right]$. As mentioned, that value is a good candidate for a debris-flow warning threshold at Subaohe basin.

\section{Conclusions and Discussions}

The characteristic rainfall, defined as the rainfall corresponding to the inflection point of debris-flow occurrence probability, is proposed as a value for warning of debris flows. The observed debris-flow and rainfall data at Jiangiia confirm the existence of such a characteristic rainfall by investigating the variation of the herein-defined catastrophic ratio. Further analysis of Jiangjia's daily rainfall histogram found that the characteristic value is in agreement with the daily rainfall with a $90 \%$ cumulative probability. Then, this finding is applied to Subaohe basin and is proposed as an estimated debris-flow warning threshold there. However, we must be careful in extending this finding to other basins where physiographic and geological settings are very different from the two study areas. The finding may be not universal and will require more case histories for verification. In spite of this, however, this method of estimating the warning rainfall threshold from the statistical characteristics of daily rainfall distribution has a significant advantage over traditional methods.

\section{Acknowledgements}

This work has been funded by the National Program on Key Basic Research Project (973 Program) (Grant No. 2008CB425802), the Knowledge Innovation Program of Chinese Academy of Sciences (Grant No. KZCX2-YW-302), and the National Natural Science Foundation of 
China (Grant No. 40701014). The authors thank the Dongchuan Debris Flow Observation and

\section{References}

Bovis, M. J. and Jakob M. 1999. The Role Of Debris Supply Conditions In Predicting Debris Flow Activity. Earth Surf. Process. Landforms 24:1039-1054.

Caine, N. 1980. The rainfall intensity: duration control of shallow landslides and debris flows. Geogr Ann A 62:23-27.

Cannon, S. H. and S. Ellen. 1985. Rainfall conditions for abundant debris avalanches, San Francisco Bay Region, California. California Geology 38: 267-272.

Casadel, M., Dietrich, W. E., and Miller, N. L. 2003. Testing a model for predicting the timing and location of shallow landslide initiation in soil-mantled landscapes. Earth Surf Proc Land 28:925-950.

Chen J. 1985. A preliminary analysis of the relation between debris flow and rainstorm at Jiangiia Gully of Dongchuan in Yunnan. Memoirs of Lanzhou Institute of Glaciology and Cryopedology of Chinese Academy of Sciences (No.4). Science Press, Beijing: 88-96. (In Chinese)

Chen, C. Y., T. C. Chen, et al. 2005. Rainfall duration and debris-flow initiated studies for real-time monitoring. Environmental Geology 47(5): 715-724.

Cui, P., Chen, X., Wang, Y., Hu, K.-H., and Li, Y. 2005. Jiangjia Ravine debris flows in south-western China, in M. Jakob and O. Hungr, eds., Debris-flow Hazards and Related Phenomena: Berlin Heidelberg, Springer-Praxis: 565-594.

Cui, P., Chen, X.Q., Zhu Y.Y. et al. The Wenchuan earthquake (May 12, 2008), Sichuan Province, China, and resulting geohazards, Nat Hazards, DOI 10.1007/s11069-009-9392-1. (preprint)

Gabet and Mudd. 2006. The mobilization of debris flows from shallow landslides. Geomorphology 74:207-218.

Godt, J. W., Baum, R. L., and Chleborad, A. F. 2006. Rainfall characteristics for shallow landsliding in Seattle, Washington, USA. Earth Surf Proc Land 31:97-110.

Iverson, R. M., Reid, M. E., and LaHusen R. G. 1997. Debrisflow mobilization from landslides, Annu. Rev. Earth Planet. Sci. 25:85-138.
Research Station, CAS, for providing the rainfall data.
Iverson, R. M. 2000. Landslide triggering by rain infiltration. Water Resources Research 36(7): 1897-1910.

Kang ZC., and Zhang SC. 1980. A preliminary analysis of the characteristics of debris flow. In: Proc. int. symp. river sed., Beijing, China, 1:213-226.

Li, J., Yuan, J.-M, et al. 1983. The main features of the mudflow in Jiang-Jia Ravine. Z. Geomorph. N. F. 27(3):325-341.

Lin, C. W., C. L. Shieh, et al. 2004. Impact of Chi-Chi earthquake on the occurrence of landslides and debris flows: example from the Chenyulan River watershed, Nantou, Taiwan. Engineering Geology 71(1-2): 49-61.

Montgomery, D. R., and Dietrich, W. E. 1994. A physically based model for the topographic control on shallow landsliding. Water Resour. Res. 3o(4):1153-1171.

Savage, W.Z., Godt, J.W., and Baum, R.L. 2003. A model for spatially and temporally distributed shallow landslide initiation by rainfall infiltration, in Rickenmann, D., and Chen, C., eds., Debris- flow hazards mitigation-mechanics, prediction and assessment: Rotterdam, Millpress: 179-187.

Terlien, M. T. J. 1998. The determination of statistical and deterministic hydrological landslide-triggering thresholds. Environmental Geology 35(2-3): 124-130.

Wieczorek, G. F. 1987. Effect of rainfall intensity and duration on debris flows in central Santa Cruz Mountains, California. Geological Society of America Reviews in Engineering Geology 7: 93-104.

Wilson, R. C. 1997. Broad-scale climatic influences on rainfall thresholds for debris flows: adapting thresholds for northern California to southern California. Geological Society of America Reviews in Engineering Geology 11:71-80.

Wilson, R. C. 2000. Climatic variations in rainfall thresholds for debris-flow activity, Proceedings of First Plinius Conference on Mediterranean Storms, Mareta, Italy, 14-16 October 1999, Claps P, Wieczorek GW (eds). European Geophysical Union: 415-442. 